\title{
Comparative composition, diversity, and abundance of oligosaccharides in early lactation milk from commercial dairy and beef cows
}

\author{
William M. Sischo, ${ }^{* 1,2}$ Diana M. Short, ${ }^{* 2}$ Mareen Geissler, $†$ Apichaya Bunyatratchata, $†$ and Daniela Barile†‡ \\ *Department of Veterinary Clinical Sciences, Food and Waterborne Disease Research, Washington State University, Pullman 99164 \\ †Department of Food Science, and \\ \#Foods for Health Institute, University of California, Davis 95616
}

\begin{abstract}
Prebiotics are nondigestible dietary ingredients, usually oligosaccharides (OS), that provide a health benefit to the host by directly modulating the gut microbiota. Although there is some information describing OS content in dairy-source milk, no information is available to describe the OS content of beef-source milk. Given the different trait emphasis between dairy and beef for milk production and calf survivability, it is plausible that OS composition, diversity, and abundance differ between production types. The goal of this study was to compare OS in milk from commercial dairy and beef cows in early lactation. Early-lactation multiparous cows (5-12 d in milk) from 5 commercial Holstein dairy herds and 5 Angus or Angus hybrid beef herds were sampled once. Milk was obtained from each enrolled cow and frozen on the farm. Subsequently, each milk sample was assessed for total solids, $\mathrm{pH}$, and OS content and relative abundance. Oligosaccharide diversity and abundance within and between samples was transformed through principal component analysis to reduce data complexity. Factors from principal component analysis were used to create similarity clusters, which were subsequently used in a multivariate logistic regression. In total, 30 OS were identified in early-lactation cow milk, including 21 distinct OS and 9 isomers with unique retention times. The majority of OS detected in the milk samples were present in all individual samples regardless of production type. Two clusters described distribution patterns of OS for the study sample; when median OS abundance was compared between the 2 clusters, we found that overall OS relative abundance was consistently greater in the cluster dominated by beef cows. For several of the structures, including those with known prebiotic effect, the difference in abun-
\end{abstract}

\footnotetext{
Received December 1, 2016

Accepted January 26, 2017.

${ }^{1}$ Corresponding author: wmsischo@vetmed.wsu.edu

${ }^{2}$ These authors contributed equally to this research.
}

dance was 2- to 4-fold greater in the beef-dominated cluster. Assuming that beef OS content in milk is the gold standard for cattle, it is likely that preweaning dairy calves are deprived of dietary-source OS. Although supplementing rations with OS is an approach to rectify this deficiency, understanding the health and productivity effects of improving OS abundance being fed to preweaning calves is a necessary next step before recommending supplementation. These studies should account for the observation that OS products are variable for both OS diversity and structural complexity, and some products may not be suitable as prebiotics.

Key words: oligosaccharides, dairy, beef, milk, prebiotics

\section{INTRODUCTION}

Diarrhea is a significant cause of morbidity and mortality in dairy calves (USDA, 2010, 2012), and there is considerable interest in approaches to reduce this disease. One idea is to affect the intestinal microbiota via the use of prebiotics to support and improve gut health (Barile and Rastall, 2013). Prebiotics are nondigestible dietary ingredients, usually oligosaccharides (OS), that provide a health benefit to the host by modulating the gut microbiota (Gibson et al., 2010; Barile and Rastall, 2013; Rastall and Gibson, 2015).

Studies of human infant intestinal microbiota have reported that infants exclusively fed breast milk develop a different bacterial profile from that of infants receiving formula milk (Harmsen et al., 2000; Jost et al., 2012; Azad et al., 2013). The difference is the relative dominance of anaerobic bacteria, with Bifidobacterium spp. being dominant in breast-fed infants and Bifidobacterium spp. sharing dominance with Bacteroides spp. in formula-fed infants (Harmsen et al., 2000). The dominance of putative health-beneficial bacteria such as Bifidobacterium spp. in the infant microbiome is driven by their ability to metabolize a variety of OS structures found in mammalian milk (Jost et al., 2012; Ruiz-Moyano et al., 2013). Humans lack enzymes to 
digest OS; consequently, these molecules pass to the hindgut where they promote growth of Bifidobacterium spp. that metabolize OS into short-chain fatty acids that are utilized by the host. Oligosaccharides in human milk are produced in the mammary gland, where 5 types of monosaccharides - glucose and galactose (hexose, Hex), $N$-acetylglucosamine (GlcNAc), fucose (Fuc), and sialic acid ( $N$-acetylneuraminic acid, NeuAc) - are added to a lactose core by action of specific glycosyltransferases. The 5 monosaccharides that comprise OS are attached in various ways through at least 12 possible linkages, resulting in many possible structural combinations (Smilowitz et al., 2014).

Significant analytical efforts have generated a human milk OS library with over 200 entries and 100 fully elucidated structures (Wu et al., 2011, 2010). In contrast, information about OS in bovine colostrum is still developing, although over 40 OS structures have been described (Tao et al., 2008; Barile et al., 2010; Mariño et al., 2011). Recent studies have identified 13 OS in bovine milk that overlap with OS structures found in human milk, including several fucosylated OS (Aldredge et al., 2013; Albrecht et al., 2014). The structural complexity of OS is a key factor determining their selective prebiotic activity. In particular, the monosaccharide sialic acid is crucial to the ability of OS to enrich beneficial bacteria while being less than ideal substrates for undesirable and pathogenic bacteria (Sela et al., 2011; Lane et al., 2012; Pacheco et al., 2015). Based on the high structural homology of several bovine acidic and neutral OS with human milk OS molecules, we predict that a similar activity will be demonstrated in bovine milk. All of the work describing OS in bovine milk is focused on dairy cattle and relatively few animals are included in these studies (Tao et al., 2008; Barile et al., 2010). Bovine milk has a lower abundance of OS compared with bovine colostrum and several structures remain to be elucidated (Tao et al., 2008). Oligosaccharides in animal milk also contain $N$-acetylgalactosamine (GalNAc) besides GlcNAc; therefore, the monosaccharide is referred to as $N$-acetylhexosamine (HexNAc), which is comprehensive of both the galactose and glucose modified form. Additionally, animal milk contain a second form of sialic acid, known as $\mathrm{N}$-gylcolylneuraminic acid (NeuGc). Similar to what is observed for human milk (Niñonuevo et al., 2008), OS abundance and structure are heterogeneous between dairy animals and breeds (Tao et al., 2009) and change over the course of lactation (Barile et al., 2010; Sundekilde et al., 2012). No information is available about the OS content of beef cow milk. Given the different trait emphasis between dairy and beef for milk production and calf survivability, it is plausible that OS composition, diversity, and abundance differ between production types. The goal of this study was to compare OS in milk from commercial dairy and beef cows in early lactation. Our hypothesis was that early-lactation beef cows will have a more abundant and diverse OS population compared with dairy cows in early lactation.

\section{MATERIALS AND METHODS}

\section{Herd Selection}

Five commercial Holstein dairy herds and 5 Angus or Angus hybrid beef herds were recruited as a convenience sample. The herds were all from Washington State and enrolled in the study between January and April 2014.

\section{Animal Enrollment}

From each enrolled herd, 5 to 8 multiparous cows between 5 and $12 \mathrm{~d}$ postcalving were identified and sampled with the help of on-farm personnel. Cows with overt clinical evidence of disease, history of recent antibiotic treatments, or reported with dystocia were excluded from the study. All experimental procedures involving cows were approved by the Washington State University, Office of Research, Institutional Animal Care and Use Committee (04497-002).

\section{Demographic Data and Biological Sample Collection}

The identification of each enrolled cow was collected along with demographic data including age or parity, production type (beef or dairy), body condition, and calving information. Body condition scoring for dairy cows was based on a score between 1 and 5 (Ferguson et al., 1994), and that for beef cows was based on a score between 1 and 9 (http://beef.unl.edu/learning/condition1b.shtml). For most beef herds, age was estimated by herd owner. Information describing herd-level feeds was collected for each farm.

From each cow, a 10- to 20-mL composite milk sample was aseptically collected. Before the sample was collected, the cow's teat ends were cleaned and disinfected. Then, after discarding any milk in the teat canals and 1 to $2 \mathrm{~mL}$ of cisternal milk, approximately $4 \mathrm{~mL}$ of milk was collected into a sterile screw-cap tube from each quarter and mixed to create a single composite sample per cow. From this sample, a 4-mL aliquot was immediately transferred to another tube. The larger volume sample was directly placed in a container with dry ice for transport to the laboratory. The smaller sample was used for an evaluation of $\mathrm{pH}$ and total solids. Once milk 
samples arrived at the laboratory, they were stored at $-80^{\circ} \mathrm{C}$. A $10-\mathrm{mL}$ blood sample was also obtained from each enrolled cow via the coccygeal vein into a serum tube.

\section{Milk Quality Assessments}

Quality assessment for total solids used a Brix refractometer as described by Moore et al. (2009). Brix measures were converted to percent solids using the following equation: percent solids $=0.997 \times$ Brix value +2.077 . We determined $\mathrm{pH}$ using a $\mathrm{pH}$ meter.

\section{Assessing Serum BHB}

From the blood samples, BHB was analyzed using the cowside Precision Xtra BHB measuring system (Abbott Laboratories, Abbott Park, IL). The test is a strip-based rapid system that requires a drop of blood to analyze BHB. Results were reported in millimoles per liter.

\section{Oligosaccharide Purification}

For oligosaccharide purification, 0.5-mL milk samples were diluted with an equal amount of nanopure water (Milli-Q purified water, $18.2 \mathrm{M} \Omega \cdot \mathrm{cm}$ at $25^{\circ} \mathrm{C}$, EMD Millipore, Billerica, MA) and defatted by centrifugation at $14,000 \times g$ for $30 \mathrm{~min}$ at $4^{\circ} \mathrm{C}$. The skim milk was collected and treated with 4 volumes of 2:1 (vol/vol) chloroform: methanol. Samples were centrifuged at 4,255 $\times g$ for $30 \mathrm{~min}$ at $4^{\circ} \mathrm{C}$ and the upper methanol layer was collected. To precipitate the protein, 2 volumes of cold ethanol were added to the skim milk, stored in the freezer for $1 \mathrm{~h}$, and the samples were centrifuged at $4,255 \times g$ for $30 \mathrm{~min}$ at $4^{\circ} \mathrm{C}$. Protein-free supernatant was collected and dried overnight in a vacuum centrifuge at $37^{\circ} \mathrm{C}$ (Quattro miVac SpeedVac, Genevac Technology, Ipswich, UK). Dried samples were rehydrated with $0.5 \mathrm{~mL}$ of nanopure water. Oligosaccharides were reduced to alditols by adding $0.05 \mathrm{~mL}$ of $1 M$ sodium borohydride $\left(\mathrm{NaBH}_{4}\right)$ and incubated at $65^{\circ} \mathrm{C}$ for $1 \mathrm{~h}$. This step is used to avoid peak splitting [due to the separation of anomers on the porous graphitized carbon (PGC) column] and thus to facilitate automated peak assignments with the library after mass spectrometry analysis. To purify OS, samples were loaded on a PGC solid-phase extraction plate (Glygen, Columbia, MD) that was activated by washing 3 times with $100 \mu \mathrm{L}$ of $80 \%$ acetonitrile containing $0.1 \%$ trifluoroacetic in water followed by 3 washings with $100 \mu \mathrm{L}$ of nanopure water. The temperature of the centrifuge was set to $23^{\circ} \mathrm{C}$ and the speed was adjusted to $241 \times g$ for each run. After loading the samples, wells were washed 6 times with $200 \mu \mathrm{L}$ of nanopure water, and OS were eluted 3 times with $40 \%$ acetonitrile containing 1\% trifluoroacetic acid in water. The concentrated OS were dried in vacuum centrifuge at $35^{\circ} \mathrm{C}$. Dried samples were rehydrated in $50 \mu \mathrm{L}$ of water, vortexed, sonicated, and vortexed again (for 20,15, and 15 min, respectively).

\section{Analysis of Oligosaccharides}

Before MS analysis, concentrated OS were diluted 100 times with nanopure water and spiked with 2 $\mu \mathrm{L}$ of 2 -fucosyllactose standard solution $(1 \mathrm{mg} / \mathrm{mL})$. The diluted samples were injected in an Agilent 6520 accurate-mass quadrupole time of flight (Q-TOF) liquid chromatograph/mass spectrometer with a microfluidic nano-electrospray chip (Agilent Technologies, Santa Clara, CA) and processed according to a previously published protocol (Aldredge et al., 2013). Briefly, the microfluidic chip consisted of a 9- $\times 0.075-$ $\mathrm{mm}$ (internal diameter, i.d.) enrichment column and a 43- $\times 0.075-\mathrm{mm}$ i.d. analytical column, both packed with $5-\mu \mathrm{m}$ porous graphitized carbon as the stationary phase. For sample loading, the capillary pump delivered $0.1 \%$ formic acid in $3.0 \%$ acetonitrile/water ( $\mathrm{vol} / \mathrm{vol}$ ) isocratically at $4.0 \mu \mathrm{L} / \mathrm{min}$. The injection volume was $2.0 \mu \mathrm{L}$ for each sample. The nanopump gradient was delivered at $0.4 \mu \mathrm{L} / \mathrm{min}$ using (A) $0.1 \%$ formic acid in 3.0\% acetonitrile/water (vol/vol), and (B) $0.1 \%$ formic acid in $90.0 \%$ acetonitrile/water (vol/ vol). Samples were eluted with $0 \% \mathrm{~B}, 0.00-2.50 \mathrm{~min}$; 0-16\% B, 2.50-20.00 min; 16-44\% B, 20.00-30.00 min; 44-100\% B, 30.00-35.00 min; and 100\% B, 35.00-45.00 min. The elution gradient was followed by a column re-equilibration at $0 \% \mathrm{~B}$ for $20 \mathrm{~min}$.

Data were acquired within the mass range of 450 to 2,500 neutral alditol in positive ionization mode with an acquisition rate of 1 spectrum/s. An internal calibration ion of 2 reference masses: 992.009798 and 1221.990637 (ESI-TOF Tuning Mix G1969-85000, Agilent Technologies) was used for continual mass calibration.

\section{Oligosaccharide Identification}

Oligosaccharides were identified from chromatograms using Mass Hunter Qualitative Analysis software version B.06.00 (Agilent Technologies). The software matched OS masses with those from an in-house annotated bovine milk OS library and generated a list of deconvoluted masses with their specific retention time using mass tolerance of $20 \mathrm{ppm}$. The identified OS compounds were extracted with a minimum abundance of 1000 counts with a maximum charge state of 2 . The 
Table 1. Farms and animals sampled to evaluate the comparative diversity and abundance of oligosaccharides in beef and dairy early lactation milk

\begin{tabular}{llccc}
\hline $\begin{array}{l}\text { Production } \\
\text { type }\end{array}$ & Farm ID & $\begin{array}{c}\text { Animals } \\
\text { enrolled (no.) }\end{array}$ & $\begin{array}{c}\text { Mean } \\
\text { age (yr) }\end{array}$ & $\begin{array}{c}\text { Median } \\
\text { age (yr) }\end{array}$ \\
\hline Beef & 1 & 6 & 5.8 & 5.5 \\
& 2 & 8 & 4.4 & 4 \\
& 3 & 5 & 8.2 & 3 \\
Dairy & 4 & 7 & 5.3 & 6.5 \\
& 5 & 6 & 6.3 & 5 \\
& 1 & 6 & 4.8 & 5 \\
Total & 2 & 6 & 5.2 & 4 \\
\hline
\end{tabular}

individual peaks for each OS type were automatically integrated using the Batch Targeted Feature Extraction from Mass Hunter Profinder software version B.06.00 (Agilent Technologies).

\section{Statistical Analyses}

Descriptive statistics for herd and animal demographics were based on frequency tabulations or measures of central tendency and variation. For multivariate analyses, the abundance values of each OS component were standardized by Z-score scaling so that, within a component, $\mu=0$ and $\mathrm{SD}=1$. As in a previous study of OS in dairy cows, this allowed for relative equal weighting of each component in subsequent analyses (Sundekilde et al., 2012). The standardized set of OS values for each sample were transformed using principal component analysis (PCA) using Proc PRINCOMP in SAS (version 9.4; SAS Institute Inc., Cary, NC). This enabled us to reduce data dimensions and within-sample OS dependency (Lattin et al., 2003). Components from PCA that accounted for $>80 \%$ of OS variation and had absolute eigenvalues $>1$ (Kaiser, 1959) were used to create similarity clusters based on partitional clustering methods (Proc FASTCLUS in SAS). Cluster membership was used as a dependent variable in logistic regression (Proc GENMOD in SAS) to assess the association between cluster and animal production type (beef or dairy) and animal-specific covariates.

\section{RESULTS}

\section{Description of Study Herds and Cows}

Sixty-five cows from 10 herds, 5 beef ( $\mathrm{n}=32$ cows) and 5 dairy $(\mathrm{n}=33$ cows) commercial operations, in Washington State were sampled. All enrolled dairy cows were Holsteins, and beef-source cows were Angus or Angus hybrids plus 4 non-Angus animals. All study cows were multiparous and ranged in age from 4 to 10 $\mathrm{yr}$, with a mean age of $5.4 \mathrm{yr}$ and median age of $5 \mathrm{yr}$ (Table 1). Enrolled dairy cows were mainly distributed between 3 and 5 yr, whereas enrolled beef cows were distributed more evenly across age groups. Days in milk ranged from 4 to $13 \mathrm{~d}$ and 5 to $13 \mathrm{~d}$ for beef and dairy, respectively. Body condition scores for dairy cows ranged from 2.00 to 3.25 with a median of 2.25 . Body condition scores for beef cows ranged from 3.5 to 8.0 with a median of 5.0. $\beta$-Hydroxybutyrate for dairy cows ranged from 0.4 to $4.2 \mathrm{mmol} / \mathrm{L}$ with a mean of 0.99 $\mathrm{mmol} / \mathrm{L}$; BHB in beef cows ranged between 0.1 and 1.1 $\mathrm{mmol} / \mathrm{L}$ with a mean of $0.38 \mathrm{mmol} / \mathrm{L}$. Using a decision point value of $\geq 1.4 \mathrm{mmol} / \mathrm{L}, 4$ dairy cows from 3 herds and no beef cows were classified as ketotic. All sampled dairy cows received similar rations, a corn-silage and alfalfa hay-based TMR. All sampled beef cows received an alfalfa and grass hay ration, with one herd (farm 2) receiving an alfalfa and wheat stubble ration.

\section{Milk Quality}

Milk quality was measured as percent milk solids and $\mathrm{pH}$. Mean percent solids were similar between dairy and beef cows, at 12.9 and 12.8, respectively. Dairy cows had more variability in solids content with a range of 7.6 to $15 \%$, whereas solids in beef cows ranged from 11.1 to $14.1 \%$. Mean milk pH was the same in dairy and beef cows, 6.4 , and similar variability, ranging from 6.1 to 6.8 .

\section{Milk Oligosaccharides}

A total of 30 OS were identified in early-lactation cow milk, including 21 distinct OS plus 9 isomers with unique retention times (Table 2). These OS were present in all milk samples regardless of production type. 
Table 2. Oligosaccharides (OS) identified in milk from 65 early lactation beef $(\mathrm{n}=32)$ and dairy cows $(\mathrm{n}=33)$ from 10 commercial operations in Washington State

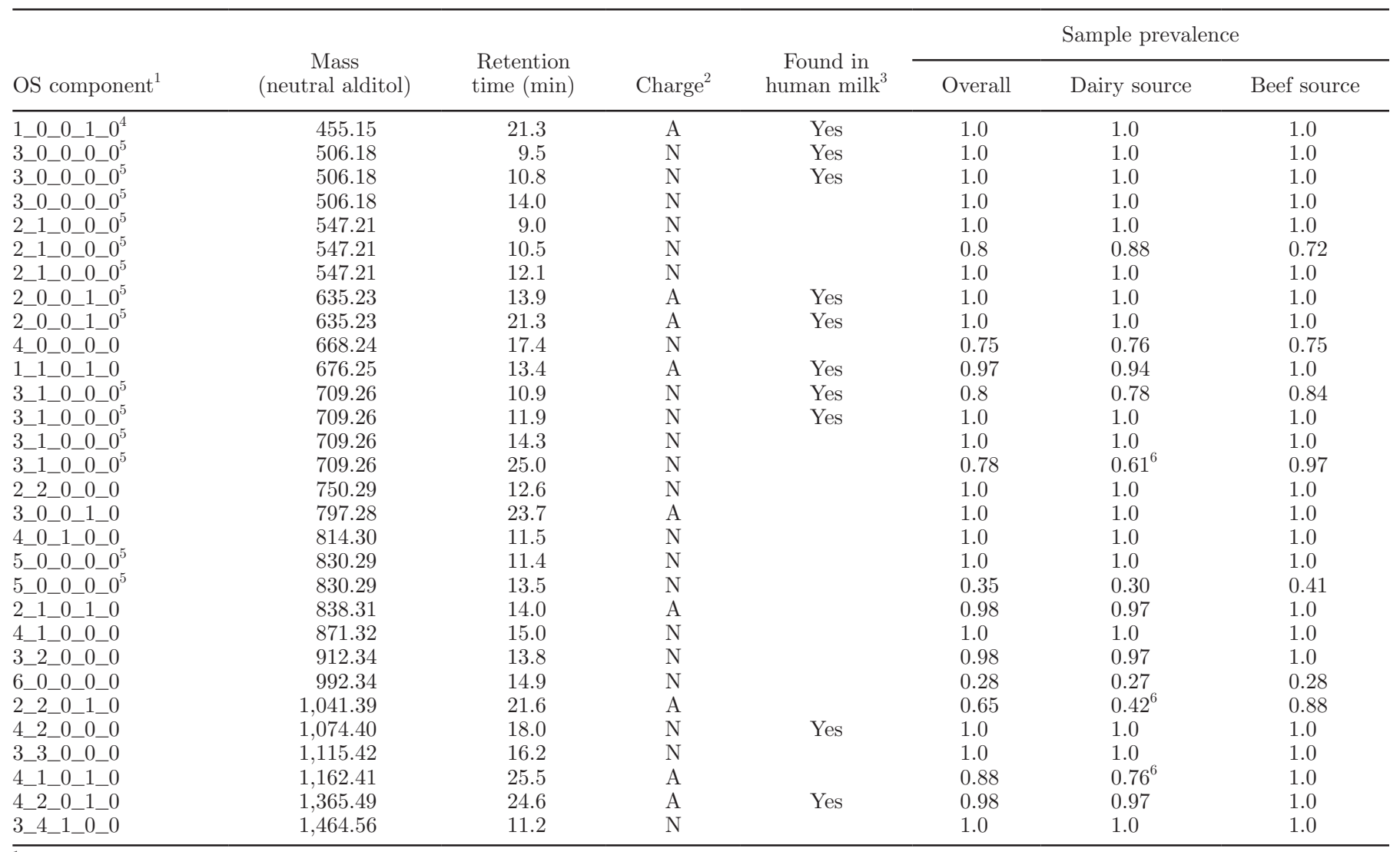

${ }^{1}$ Thirty OS components are listed in order of increasing mass. The OS composition is shown as number of individual monosaccharides in the order Hex-HexNAc-Fuc-NeuAc-NeuGc, where Hex $=$ hexose (glucose or galactose), HexNAc $=N$-acetylhexosamine, Fuc $=$ fucose, NeuAc $=$ $N$-acetylneuraminic acid (sialic acid), and NeuGc $=N$-glycolylneuraminic acid (sialic acid). Component prevalence is stratified by dairy and beef breed source

${ }^{2} \mathrm{~N}=$ neutral, $\mathrm{A}=$ acidic

${ }^{3} \mathrm{OS}$ component also identified in human milk by Wu et al. (2010).

${ }^{4}$ Potential fragment of 2_0_0_1_0.

${ }^{5}$ Isomers.

${ }^{6}$ OS prevalence was significantly different in sampled dairy cows than in sampled beef cows $(P \leq 0.05)$.

Three OS, with composition $3 \_1 \_0 \_0 \_0,2 \_2 \_0 \_1 \_0$, and $4 \_1 \_0 \_1 \_0$ (composition denoted by the order of monosaccharides Hex-GlcNAc-Fuc-NeuAc-NeuGc), were more prevalent in beef cows than in dairy cows (Table 2). Four OS were detected in equivalently low prevalence in beef and dairy cows. Ten OS found in this study are also prevalent in human milk.

Using PCA, the 30 OS structures were reduced to 8 principal components with eigenvalues $>1$ and explaining $>80 \%$ of the total OS variance. These were used to create similarity clusters. From these data, 2 clusters described distribution patterns of OS for our study sample (Table 3). When we compared median OS abundance between the 2 clusters, we found that overall OS abundance was consistently greater in cluster 2 (Table 4 ).
Because values of abundance within individual OS components varied by factors of 10 , relative median abundance was calculated for each OS component. Relative median OS values between the 2 clusters were calculated for each OS using cluster 1 abundance value

Table 3. Distribution of early lactation cows stratified by production type (beef and dairy) to oligosaccharide (OS) clusters $^{1}$

\begin{tabular}{lccc}
\hline OS cluster & Beef & Dairy & Total \\
\hline 1 & 8 & 22 & 30 \\
2 & 24 & 11 & 35 \\
Total & 32 & 33 & 65 \\
\hline
\end{tabular}

${ }^{1}$ Clusters were formed using the first 8 principal components (which explained $80 \%$ of the total OS variability and eigenvalues for components $>1$ ). 
Table 4. Oligosaccharides (OS) identified in milk from early lactation beef and dairy cows from 10 commercial operations in Washington State ${ }^{1}$

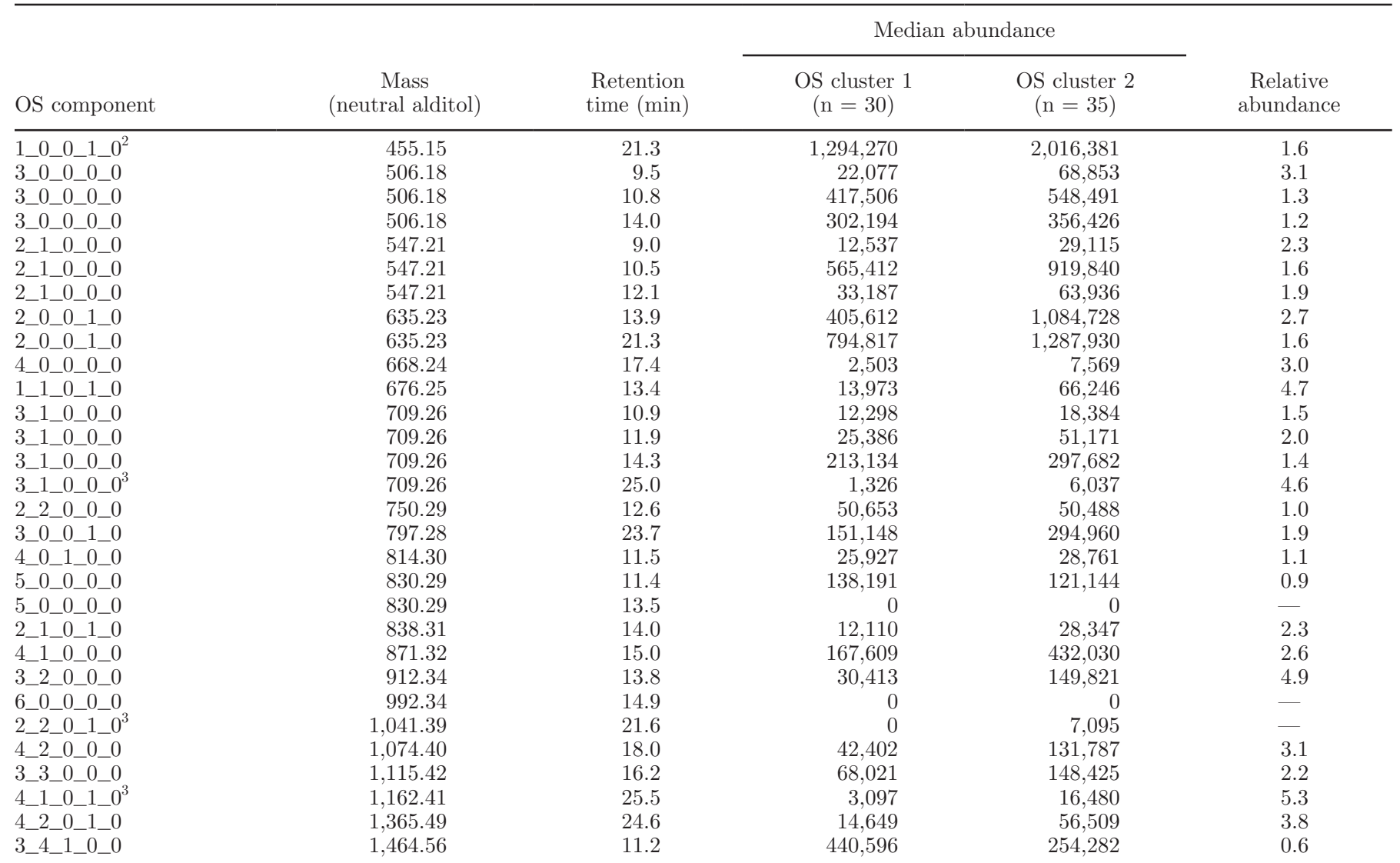

${ }^{1}$ Median abundance or peak area for each of the 30 detected OS components by cluster are listed. The OS composition is shown as number of individual monosaccharides in the order Hex-HexNAc-Fuc-NeuAc-NeuGc, where Hex $=$ hexose (glucose or galactose), HexNAc $=N$-acetylhexosamine, Fuc $=$ fucose, NeuAc $=N$-acetylneuraminic acid (sialic acid), and NeuGc $=N$-glycolylneuraminic acid (sialic acid). Relative median abundance is shown as the ratio of cluster 2 to cluster 1 median abundance.

${ }^{2}$ Potential fragment of $2 \_0 \_0 \_1 \_0$.

${ }^{3} \mathrm{OS}$ with prebiotic potential.

as the denominator. The ratios were $>2$ for 14 of the components, and 4 components had $>4$-fold higher values in cluster 2 compared with cluster 1 (Table 4, highlighted). Three OS identified in cluster 2 (3_1_0_0_0, $2 \_2 \_0 \_1 \_0$, and $\left.4 \_1 \_0 \_1 \_0\right)$ were more abundant for both neutral and sialylated molecular structures, which are notable for their bifidogenic potential, compared with the abundance observed in cluster 1 .
Multivariate logistic regression using cluster membership as the dependent variable found 2 important associations: the odds ratio of beef cows belonging to cluster 2 was 20.8 (95\% CI: 3.8-113.0) compared with being a dairy cow, and the odds ratio of 5 - to 6-yr-old cows belonging to cluster 2 was 7.0 (95\% CI, 1.2-39.4) compared with 3- to 4-yr-old cows (Table 5). This latter effect was independent of cow production type. We

Table 5. Logistic regression modeling the association between oligosaccharide cluster membership and animal production type (beef and dairy) and age category. The model was estimating the odds of membership in cluster 2 compared with cluster 1

\begin{tabular}{|c|c|c|c|c|c|}
\hline Variable & Category & Estimate & Odds ratio & Lower $95 \%$ CI & Upper $95 \%$ CI \\
\hline Production type & $\begin{array}{l}\text { Beef } \\
\text { Dairy }\end{array}$ & $\begin{array}{c}3.0 \\
\text { Referent }\end{array}$ & 20.8 & 3.8 & 113 \\
\hline Age & $\begin{array}{l}5-6 \text { yr }(\mathrm{n}=23) \\
7-10 \text { yr }(\mathrm{n}=17) \\
3-4 \text { yr }(\mathrm{n}=25)\end{array}$ & $\begin{array}{c}2.0 \\
-0.4 \\
\text { Referent }\end{array}$ & $\begin{array}{l}7 \\
0.6\end{array}$ & $\begin{array}{l}1.2 \\
0.1\end{array}$ & $\begin{array}{c}39.4 \\
3\end{array}$ \\
\hline
\end{tabular}


found no associations of BHB category or milk quality parameters with cluster membership.

\section{DISCUSSION}

The major finding of this study was that although OS structures prevalent in early lactation beef and dairy fresh milk were observed in both production types, the relative abundance of most components was greater in the beef-dominated OS cluster 2 compared with those observed in the dairy-dominated OS cluster 1. A previous study comparing dairy breeds (Jersey vs. HolsteinFriesian) also found qualitative and quantitative differences in OS between the breeds (Sundekilde et al., 2012). Jersey breed cows, which tend to have lower milk yield and greater relative milk solids compared with Holsteins, had more complex and abundant sialylated OS compared with Holsteins. Additionally, Jersey milk contained greater levels of neutral OS associated with prebiotic effects for Bifidobacterium spp. (LoCascio et al., 2007; Barile et al., 2010). In our study, OS identified in the beef-dominated cluster were more abundant for both neutral and sialylated OS and for bifidogenic neutral OS compared with those observed in the dairydominated cluster. In fact, the beef-predominant oligosaccharides $3 \_1 \_0 \_0 \_0,2 \_2 \_0 \_1 \_0$, and $4 \_1 \_0 \_1 \_0$ contain structural elements that make them potential prebiotics. Oligosaccharide 3_1_0_0_0 contains $N$ acetylglucosamine and belongs to the "lacto- $N$-tetrose/ lacto- $N$-neotetraose-type," which is also known as "bifidus factor" (Jao et al., 1978). Jao et al. (1978) demonstrated that human and bovine milk contain growth factors required for growth of Bifidobacterium bifidum to high cell densities. By studying the growth of $B$. bifidum in the presence of various carbohydrates that are known components of milk OS, they demonstrated that the growth-promoting effect of $N$-acetylglucosamine was superior to that of $N$-acetylgalactosamine and $N$-acetylmannosamine. Therefore, OS grouped as lacto- $N$-tetrose and lacto- $N$-neotetraose are called bifidus factors, referring to their ability to promote growth of bifidobacteria. Oligosaccharides 2_2_0_1_0 and 4_1_0_1_0 both contain bound sialylic acid (NeuAc), which has been demonstrated to be a key factor in determining selective prebiotic activity (Yu et al., 2013). Considering that the mucosal immune system is not mature at birth, milk OS play an important means of providing passive immunity and affecting development of the mucosal immune system. Across host species, the first bacteria to be established in the gut affect immune response, making the gut environment more favorable to their own survival and less favorable to competing species (Gensollen et al., 2016). Thus, the first bacteria to colonize the gut are important in determining life- long benefits, and the OS present in milk play a key role in establishing the makeup of such microbiota.

In this context, our results may suggest that the selection process for beef to optimize survivability of calf crop may also optimize milk components for calf health compared with dairy cows, which are selected to maximize milk production and optimize milk components for commercial use. It is also notable that cluster 2 included some dairy cows and cluster 1 some beef cows, so OS profiles are not solely driven by selection for production type.

As observed previously (Barile et al., 2009, 2010; Albrecht et al., 2014), there are OS structures in common between cattle and humans. Of the 30 OS identified in our study, 10 have been observed in human milk (Table $2)$.

This study did not directly measure fat, protein components, lactose, or milk volume but we observed no difference in percent total solids between beef and dairy cows, although the range for total solids was greater for dairy compared with beef. Differences in milk components between dairy and beef breeds are noted. In one report, beef cattle at 30 DIM produced $10.6 \mathrm{~kg} / \mathrm{d}$ of milk with $2.1 \%$ fat, $3.0 \%$ protein, and $5.4 \%$ lactose (Radunz et al., 2010). For comparison, a metaanalysis that summarized more than 800 data means from studies involving primarily Holsteins at 50 to 337 DIM reported, on average, $31.1 \mathrm{~kg} / \mathrm{d}$ of milk with $3.6 \%$ fat, $3.1 \%$ protein, and $4.8 \%$ lactose (Daniel et al., 2016). The most notable difference was in production volume and, to a lesser degree, percent fat, with both being greater in dairy cows. The relative differences in components (fat, protein, and lactose) were much smaller than we observed for the relative differences for OS abundance between beef and dairy.

We detected diet composition differences between production types, although diet composition was consistent within production type. These differences may explain in part (but not fully) the observed differences in OS abundance between cattle production types. As seen in Table 3, dairy cows were observed in beef-dominated cluster 2 and beef cows were observed in dairydominated cluster 1 . In addition, cows within herds did not always cluster together (data not shown). Both of these observations suggest that diet exposure by itself was not the sole driver of OS diversity and abundance.

Age was independently associated with OS cluster membership: 5- to 6 -yr-old cows were more likely to be associated with the beef-dominated cluster compared with 3- to 4-yr-old cows. The oldest category of cows (7 to $10 \mathrm{yr}$ old) did not differ in OS cluster membership compared with the youngest cows in this study. Age does influence milk quality; older animals produce milk and colostrum with higher levels of protein and fat, and 
studies in dairy cows suggest that peak milk production efficiency occurs in lactation 5, at approximately $7 \mathrm{yr}$ of age (Ray et al., 1992).

The significance of our study findings is based on identifying 30 prevalent OS that were observed in both dairy and beef animals with consistent relative abundance differences favoring beef cattle. In addition, the data suggest a functional prebiotic advantage for the OS in beef-source early lactation milk. Assuming that beef OS content in milk is the gold standard for cattle and ad libitum milk consumption for beef calves is approximately $7 \mathrm{~kg} / \mathrm{d}$ (Fiems et al., 2008; Liu et al., 2015) and for dairy calves approximately $9 \mathrm{~kg} / \mathrm{d}$ (Jasper and Weary, 2002), then a dairy calf fed ad libitum is likely deprived of dietary-source OS. Because many calves are restricted in milk consumption to 4 to $5 \mathrm{~kg} / \mathrm{d}$, these calves are severely deprived of dietary-source OS.

These findings suggest an opportunity to provide a health benefit to dairy calves through OS supplementation. The human literature highlights the importance of a diverse and abundant OS profile to promote gut colonization by health-beneficial bacterial species such as Bifidobacterium spp. (Jost et al., 2012; Ruiz-Moyano et al., 2013). The challenge in finding appropriate and effective supplementation is that many available supplements are simple structures from yeast cell walls or a product of bacterial or fungal-derived enzymatic trans-glycosylation of lactose and do not mimic the diversity of natural OS. In contrast to the prebiotic benefits, some OS have the potential to exert exclusionary effects due to receptor analog functions and thus may promote gut health by preventing binding of pathogens and their effector molecules to the gut (Crane et al., 1994; Shoaf-Sweeney et al., 2009). Some studies have looked at OS supplementation to support transfer of passive immunity in neonatal animals. This strategy is also aimed at leveraging OS bacterial binding attributes to mitigate the adverse effects of bacterial contamination of colostrum on absorption of maternal $\operatorname{IgG}$ in the neonatal gut. One study comparing OS colostrum supplementation with 3 OS (a mannan-oligosaccharide and 2 galacto-oligosaccharides) did demonstrate an improvement in $\mathrm{IgG}$ absorption in the face of bacterial contamination compared with a lactose control (Short et al., 2016). Another study did not find a similar effect following mannan-oligosaccharide supplementation to colostrum replacer. This difference may have been related to differences in bacterial contamination between the studies and therefore to the lesser opportunity for OS to exert a benefit (Brady et al., 2015). Relatively few studies have evaluated dairy calf health outcomes following OS supplementation and these have reported mixed outcomes (Quigley et al., 1997; Uyeno et al.,
2015). Some differences in study outcomes, particularly with galacto-oligosaccharide supplementation, are likely because these products are not identical with respect to composition or complexity. A comparison of 7 commercial galacto-oligosaccharides found a difference between preparations in number and types of detected structures, degree of polymerization, and distribution of glycosidic linkages (van Leeuwen et al., 2014, 2016). Given the importance of complexity and diversity for the effectiveness of OS as a prebiotic, it is important to remember that different supplements may elicit different responses.

\section{CONCLUSIONS}

The relative abundance of OS, particularly those structures with prebiotic potential, were greater in beef-source milk compared with dairy-source milk, which suggests that dairy calves are likely deprived of diet-source OS.

\section{ACKNOWLEDGMENTS}

The authors thank Katy Heaton (Washington State University, Pullman) for help in sample collection and Cora J. Morgan (writing consultant, Forest Hill, CA) for editing this manuscript. This research was supported in part by funding from the Bill and Melinda Gates Foundation, National Institutes of Health awards R01AT007079 and R01AT008759, USDA:NIFA Hatch project 232719 and USDA:NIFA 2014-05266 from the National Institute of Food and Agriculture (Washington, DC). The authors particularly thank the beef and dairy producers who graciously assisted in this project.

\section{REFERENCES}

Albrecht, S., J. A. Lane, K. Mariño, K. A. Al Busadah, S. D. Carrington, R. M. Hickey, and P. M. Rudd. 2014. A comparative study of free oligosaccharides in the milk of domestic animals. Br. J. Nutr. 111:1313-1328. https://doi.org/10.1017/S0007114513003772.

Aldredge, D. L., M. R. Geronimo, S. Hua, C. C. Nwosu, C. B. Lebrilla, and D. Barile. 2013. Annotation and structural elucidation of bovine milk oligosaccharides and determination of novel fucosylated structures. Glycobiology 23:664-676. https://doi. org/10.1093/glycob/cwt007.

Azad, M. B., T. Konya, H. Maughan, D. S. Guttman, C. J. Field, R. S. Chari, M. R. Sears, A. B. Becker, J. A. Scott, and A. L. Kozyrskyj. 2013. Gut microbiota of healthy Canadian infants: profiles by mode of delivery and infant diet at 4 months. CMAJ 185:385-394. https://doi.org/10.1503/cmaj.121189.

Barile, D., M. Marotta, C. Chu, R. Mehra, R. Grimm, C. B. Lebrilla, and J. B. German. 2010. Neutral and acidic oligosaccharides in Holstein-Friesian colostrum during the first 3 days of lactation measured by high performance liquid chromatography on a microfluidic chip and time-of-flight mass spectrometry. J. Dairy Sci. 93:3940-3949. https://doi.org/10.3168/jds.2010-3156. 
Barile, D., and R. A. Rastall. 2013. Human milk and related oligosaccharides as prebiotics. Curr. Opin. Biotechnol. 24:214-219. https://doi.org/10.1016/j.copbio.2013.01.008.

Barile, D., N. Tao, C. B. Lebrilla, J.-D. Coisson, M. Arlorio, and J. B. German. 2009. Permeate from cheese whey ultrafiltration is a source of milk oligosaccharides. Int. Dairy J. 19:524-530. https:// doi.org/10.1016/j.idairyj.2009.03.008

Brady, M. P., S. M. Godden, and D. M. Haines. 2015. Supplementing fresh bovine colostrum with gut-active carbohydrates reduces passive transfer of immunoglobulin G in Holstein dairy calves. J. Dairy Sci. 98:6415-6422. https://doi.org/10.3168/jds.2015-9481.

Crane, J. K., S. S. Azar, A. Stam, and D. S. Newburg. 1994. Oligosaccharides from human milk block binding and activity of the Escherichia coli heat-stable enterotoxin (STa) in T84 intestinal cells. J. Nutr. 124:2358-2364.

Daniel, J. B., N. C. Friggens, P. Chapoutot, H. van Laar, and D. Sauvant. 2016. Milk yield and milk composition responses to change in predicted net energy and metabolizable protein: A meta-analysis. Animal 10:1975-1985. https://doi.org/10.1017/ S1751731116001245.

Ferguson, J. D., D. T. Galligan, and N. Thomsen. 1994. Principal descriptors of body condition score in Holstein Cows. J. Dairy Sci. 77:2695-2703. https://doi.org/10.3168/jds.S0022-0302(94)77212$\mathrm{X}$.

Fiems, L. O., W. V. Caelenbergh, S. D. Campeneere, and D. L. D. Brabander. 2008. Effect of dam factors on milk intake and performance of Belgian Blue suckling calves. Animal 2:135-140. https:// doi.org/10.1017/S1751731107000870.

Gensollen, T., S. S. Iyer, D. L. Kasper, and R. S. Blumberg. 2016. How colonization by microbiota in early life shapes the immune system. Science 352:539-544. https://doi.org/10.1126/science.aad9378.

Gibson, G. R., K. P. Scott, R. A. Rastall, K. M. Tuohy, A. Hotchkiss, A. Dubert-Ferrandon, M. Gareau, E. F. Murphy, D. Saulnier, G. Loh, S. Macfarlane, N. Delzenne, Y. Ringel, G. Kozianowski, R. Dickmann, I. Lenoir-Wijnkoop, C. Walker, and R. Buddington. 2010. Dietary prebiotics: Current status and new definition. Food Sci. Technol. Bull. Funct. Foods 7:1-19.

Harmsen, H. J., A. C. Wildeboer-Veloo, G. C. Raangs, A. A. Wagendorp, N. Klijn, J. G. Bindels, and G. W. Welling. 2000. Analysis of intestinal flora development in breast-fed and formula-fed infants by using molecular identification and detection methods. J. Pediatr. Gastroenterol. Nutr. 30:61-67.

Jao, Y. C., E. M. Mikolajcik, and P. M. T. Hansen. 1978. Growth of Bifidobacterium bifidum var. pennsylvanicus in laboratory media supplemented with amino sugars and spent broth from Escherichia coli. J. Food Sci. 43:1257-1260. https://doi. org/10.1111/j.1365-2621.1978.tb15282.x.

Jasper, J., and D. M. Weary. 2002. Effects of ad libitum milk intake on dairy calves. J. Dairy Sci. 85:3054-3058. https://doi.org/10.3168/ jds.S0022-0302(02)74391-9.

Jost, T., C. Lacroix, C. P. Braegger, and C. Chassard. 2012. New insights in gut microbiota establishment in healthy breast fed neonates. PLoS One 7:e44595 https://doi.org/10.1371/journal. pone.0044595.

Kaiser, H. F. 1959. Computer program for varimax rotation in factor analysis. Educ. Psychol. Meas. 19:413-420. https://doi. org $/ 10.1177 / 001316445901900314$.

Lane, J. A., K. Mariño, P. M. Rudd, S. D. Carrington, H. Slattery, and R. M. Hickey. 2012. Methodologies for screening of bacteria-carbohydrate interactions: Anti-adhesive milk oligosaccharides as a case study. J. Microbiol. Methods 90:53-59. https://doi.org/10.1016/j. mimet.2012.03.017.

Lattin, J. M., J. D. Carroll, and P. E. Green. 2003. Principal components analysis. Pages 83-117 in Analyzing Multivariate Data. J. M. Lattin, J. D. Carroll, and P. E. Green, ed. Brooks-Cole, Belmont, CA.

Liu, T., A. R. Mays, K. E. Turner, J. P. Wu, and M. A. Brown. 2015. Relationships of milk yield and quality from six breed groups of beef cows to preweaning average daily gain of their calves. J. Anim. Sci. 93:1859-1864. https://doi.org/10.2527/jas.2014-8220.
LoCascio, R. G., M. R. Ninonuevo, S. L. Freeman, D. A. Sela, R. Grimm, C. B. Lebrilla, D. A. Mills, and J. B. German. 2007. Glycoprofiling of bifidobacterial consumption of human milk oligosaccharides demonstrates strain specific, preferential consumption of small chain glycans secreted in early human lactation. J. Agric. Food Chem. 55:8914-8919. https://doi.org/10.1021/jf0710480.

Mariño, K., J. A. Lane, J. L. Abrahams, W. B. Struwe, D. J. Harvey, M. Marotta, R. M. Hickey, and P. M. Rudd. 2011. Method for milk oligosaccharide profiling by 2-aminobenzamide labeling and hydrophilic interaction chromatography. Glycobiology 21:1317-1330. https://doi.org/10.1093/glycob/cwr067.

Moore, D. A., J. Taylor, M. L. Hartman, and W. M. Sischo. 2009. Quality assessments of waste milk at a calf ranch. J. Dairy Sci. 92:3503-3509. https://doi.org/10.3168/jds.2008-1623.

Niñonuevo, M. R., P. D. Perkins, J. Francis, L. M. Lamotte, R. G. LoCascio, S. L. Freeman, D. A. Mills, J. B. German, R. Grimm, and C. B. Lebrilla. 2008. Daily variations in oligosaccharides of human milk determined by microfluidic chips and mass spectrometry. J. Agric. Food Chem. 56:618-626. https://doi.org/10.1021/ jf071972u.

Pacheco, A. R., D. Barile, M. A. Underwood, and D. A. Mills. 2015. The impact of the milk glycobiome on the neonate gut microbiota. Annu. Rev. Anim. Biosci. 3:419-445. https://doi.org/10.1146/ annurev-animal-022114-111112.

Quigley, J. D., J. J. Drewry, L. M. Murray, and S. J. Ivey. 1997. Body weight gain, feed efficiency, and fecal scores of dairy calves in response to galactosyl-lactose or antibiotics in milk replacers. J. Dairy Sci. 80:1751-1754. https://doi.org/10.3168/jds.S00220302(97)76108-3.

Radunz, A. E., F. L. Fluharty, M. L. Day, H. N. Zerby, and S. C. Loerch. 2010. Prepartum dietary energy source fed to beef cows: I. Effects on pre- and postpartum cow performance. J. Anim. Sci. 88:2717-2728. https://doi.org/10.2527/jas.2009-2744.

Rastall, R. A., and G. R. Gibson. 2015. Recent developments in prebiotics to selectively impact beneficial microbes and promote intestinal health. Curr. Opin. Biotechnol. 32:42-46. https://doi. org/10.1016/j.copbio.2014.11.002.

Ray, D. E., T. J. Halbach, and D. V. Armstrong. 1992. Season and lactation number effects on milk production and reproduction of dairy cattle in Arizona. J. Dairy Sci. 75:2976-2983. https://doi. org/10.3168/jds.S0022-0302(92)78061-8.

Ruiz-Moyano, S., S. M. Totten, D. A. Garrido, J. T. Smilowitz, J. B. German, C. B. Lebrilla, and D. A. Mills. 2013. Variation in consumption of human milk oligosaccharides by infant gut-associated strains of Bifidobacterium breve. Appl. Environ. Microbiol. 79:6040-6049. https://doi.org/10.1128/AEM.01843-13.

Shoaf-Sweeney, K. D., and R. W. Hutkins. 2009. Adherence, antiadherence, and oligosaccharides preventing pathogens from sticking to the host. Adv. Food Nutr. Res. 55:101-161. https://doi. org/10.1016/S1043-4526(08)00402-6.

Sela, D. A., Y. Li, L. Lerno, S. Wu, A. M. Marcobal, J. B. German, X. Chen, C. B. Lebrilla, and D. A. Mills. 2011. An infant-associated bacterial commensal utilizes breast milk sialyloligosaccharides. J. Biol. Chem. 286:11909-11918. https://doi.org/10.1074/jbc. M110.193359.

Short, D. M., D. A. Moore, and W. M. Sischo. 2016. A randomized clinical trial evaluating the effects of oligosaccharides on transfer of passive immunity in neonatal dairy calves. J. Vet. Intern. Med. 30:1381-1389. https://doi.org/10.1111/jvim.13949.

Smilowitz, J. T., C. B. Lebrilla, D. A. Mills, J. B. German, and S. L. Freeman. 2014. Breast milk oligosaccharides: Structure-function relationships in the neonate. Annu. Rev. Nutr. 34:143-169. https://doi.org/10.1146/annurev-nutr-071813-105721.

Sundekilde, U. K., D. Barile, M. Meyrand, N. A. Poulsen, L. B. Larsen, C. B. Lebrilla, J. B. German, and H. C. Bertram. 2012. Natural variability in bovine milk oligosaccharides from Danish Jersey and Holstein-Friesian breeds. J. Agric. Food Chem. 60:6188-6196. https://doi.org/10.1021/jf300015j.

Tao, N., E. J. DePeters, S. Freeman, J. B. German, R. Grimm, and C. B. Lebrilla. 2008. Bovine milk glycome. J. Dairy Sci. 91:3768-3778. https://doi.org/10.3168/jds.2008-1305. 
Tao, N., E. J. DePeters, J. B. German, R. Grimm, and C. B. Lebrilla. 2009. Variations in bovine milk oligosaccharides during early and middle lactation stages analyzed by high-performance liquid chromatography-chip/mass spectrometry. J. Dairy Sci. 92:2991-3001. https://doi.org/10.3168/jds.2008-1642.

USDA. 2010. Dairy 2007, Heifer Calf Health and Management Practices on U.S. Dairy Operations. USDA:APHIS:VS, CEAH, Fort Collins, CO.

USDA. 2012. Dairy Heifer Raiser, 2011: An Overview of Operations that Specialize in Raising Dairy Heifers. National Animal Health Monitoring System (NAHMS). USDA:APHIS:VS, CEAH, Fort Collins, CO.

Uyeno, Y., S. Shigemori, and T. Shimosato. 2015. Effect of probiotics/ prebiotics on cattle health and productivity. Microbes Environ. 30:126-132. https://doi.org/10.1264/jsme2.ME14176.

van Leeuwen, S. S., B. J. H. Kuipers, L. Dijkhuizen, and J. P. Kamerling. 2014. 1H NMR analysis of the lactose/ $\beta$-galactosidasederived galacto-oligosaccharide components of Vivinal ${ }^{\circledR}$ GOS up to DP5. Carbohydr. Res. 400:59-73. https://doi.org/10.1016/j carres.2014.08.012.

van Leeuwen, S. S., B. J. H. Kuipers, L. Dijkhuizen, and J. P. Kamerling. 2016. Comparative structural characterization of 7 commercial galacto-oligosaccharide (GOS) products. Carbohydr. Res. 425:48-58. https://doi.org/10.1016/j.carres.2016.03.006.

Wu, S., R. Grimm, J. B. German, and C. B. Lebrilla. 2011. Annotation and structural analysis of sialylated human milk oligosaccharides. J. Proteome Res. 10:856-868. https://doi.org/10.1021/pr101006u.

Wu, S., N. Tao, J. B. German, R. Grimm, and C. B. Lebrilla. 2010 The development of an annotated library of neutral human milk oligosaccharides. J. Proteome Res. 9:4138-4151. https://doi. org $/ 10.1021 / \operatorname{pr} 100362 \mathrm{f}$.

Yu, Z. T., C. Chen, and D. S. Newburg. 2013. Utilization of major fucosylated and sialylated human milk oligosaccharides by isolated human gut microbes. Glycobiology 23:1281-1292. https://doi org/10.1093/glycob/cwt065. 